\title{
Measurements and comparison of primary biological aerosol above and below a tropical forest canopy using a dual channel fluorescence spectrometer
}

\author{
A. M. Gabey ${ }^{1}$, M. W. Gallagher ${ }^{1}$, J. Whitehead ${ }^{1}$, J. R. Dorsey ${ }^{1}$, P. H. Kaye ${ }^{2}$, and W. R. Stanley ${ }^{2}$ \\ ${ }^{1}$ Centre for Atmospheric Science, University of Manchester, M13 9PL, UK \\ ${ }^{2}$ Science and Technology Research Institute, University of Hertfordshire, AL10 9AB, UK
}

Received: 25 August 2009 - Published in Atmos. Chem. Phys. Discuss.: 11 September 2009

Revised: 11 April 2010 - Accepted: 19 April 2010 - Published: 17 May 2010

\begin{abstract}
Aerosol particle size distributions were measured below and above a tropical rainforest canopy in Borneo, Malaysia, in June/July 2008 using the WIBS-3: a single particle dual channel fluorescence spectrometer. Material in the size range $0.8-20 \mu \mathrm{m}$ was characterized according to optical equivalent diameter $\left(D_{\mathrm{P}}\right)$, morphology and fluorescence at $310-400 \mathrm{~nm}$ and $400-600 \mathrm{~nm}$ following excitation at $280 \mathrm{~nm}$ and $370 \mathrm{~nm}$ respectively. Particles fluorescent after both excitations are likely to be fluorescent primary biological aerosol particles (FBAP).

Measured FBAP number concentration $\left(N_{\mathrm{FBAP}}\right)$ at both sites exhibited clear diurnal cycles. The largest variability was observed in the understorey, where $N_{\mathrm{FBAP}}$ reached a minimum of $50-100 \mathrm{~L}^{-1}$ in late morning. In mid afternoon it exhibited strong transient fluctuations as large as $4000 \mathrm{~L}^{-1}$ that were followed by sustained concentrations of $1000-2500 \mathrm{~L}^{-1}$ that reduced steadily between midnight and sunrise. Above the canopy FBAP number ranged from 50$100 \mathrm{~L}^{-1}$ during the daytime to $200-400 \mathrm{~L}^{-1}$ at night but did not exhibit the transient enhancements seen in the understorey. The strong FBAP fluctuations were attributed to the release of fungal spores below the canopy and appeared to be linked to elevated relative humidity.

The mean FBAP number fraction in the size range $0.8 \mu \mathrm{m}<D_{\mathrm{P}}<20 \mu \mathrm{m}$ was $55 \%$ in the understorey and $28 \%$ above canopy. A size mode at $2 \mu \mathrm{m}<D_{\mathrm{P}}<4 \mu \mathrm{m}$ appears at both sites and is primarily FBAP, which dominated the coarse $\left(D_{\mathrm{P}} \geq 2.5 \mu \mathrm{m}\right)$ number concentration at both sites, accounting for $75 \%$ in the understorey and 57\% above the canopy. In contrast, the concentration of non-fluorescent particles
\end{abstract}

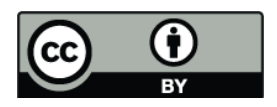

Correspondence to: A. M. Gabey (andrew.m.gabey@postgrad.manchester.ac.uk)
$\left(N_{\mathrm{NON}}\right)$ at both sites was typically $200-500 \mathrm{~L}^{-1}$, the majority of which occupied a size mode at $0.8<D_{\mathrm{P}}<1.5 \mu \mathrm{m}$. Enhanced understorey $N_{\text {NON }}$ was observed daily in midafternoon and also at midday on three occasions: the former coincided with the FBAP enhancements and measured approximately $10 \%$ of their magnitude; the latter occurred independently of the $N_{\mathrm{FBAP}}$ diurnal cycle and comprised particles smaller than $2 \mu \mathrm{m}$. Particle diameter of 3-5 $\mu \mathrm{m}$ is consistent with smaller fungal spores, though absolute identification of biological species is not possible with the UVLIF technique. Based on the measured FBAP and nonfluorescent particle abundances and their observed recovery times following rain showers, FBAP originated beneath the canopy while the non-fluorescent material was transported from further away. It is concluded that these separate sources contributed the majority of the aerosol measured by the WIBS-3 at both sites.

\section{Introduction}

Primary Biological Aerosol (PBA) is the subset of the atmospheric aerosol that is comprised of anything discernibly biological in nature, including plant and insect debris, fungal and plant spores, pollens, cells, viruses, bacteria and partially decomposed material. Its abundance in the atmosphere is poorly constrained and potential feedback on cloudhydrological pathways is not yet included in climate models. The ubiquity of PBA in the atmosphere - particularly the fraction swept into cloud-forming regions (e.g. Jaenicke and Matthias-Maser, 1993), residing in the atmosphere for weeks and travelling up to $1000 \mathrm{~km}$ (e.g. Prospero et al., 2005) - is where much of the current PBA research interest is

Published by Copernicus Publications on behalf of the European Geosciences Union. 
focussed (Möhler et al., 2007). Its transport has implications for global biodiversity and disease transmission and there are potential effects on cloud microphysical processes because of the ability of PBA to act as "giant" cloud condensation nuclei $(\mathrm{CCN})$ and ice nuclei (IN) at temperatures up to $-2{ }^{\circ} \mathrm{C}$ (Deihl et al., 2001, 2002). Global PBA mass is thought to be dominated by spores and plant debris (e.g. Winiwarter et al., 2009) since these PBA particles are normally the largest and most widely emitted by vegetated areas. Tropical rainforests are potentially strong sources of atmospheric PBA because of the dense, year-round vegetation and strong convective up draughts found there. Less characterised is the how the canopy itself interacts with and contributes to the transport of PBA to the free atmosphere. Understanding this variable is a logical first step in connecting estimated PBA production and its atmospheric significance in tropical regions.

\subsection{Conventional sampling methods}

PBA are traditionally sampled by impaction or sedimentation of particles onto an adhesive substrate such as agar coated Petri dishes (e.g. Andersen impactor), microscope slides (e.g. Alergenco MK-3) or sticky tape (e.g. Hirst spore trap). In the case of smaller or more fragile particles an impinger is used (e.g. AGI-30), which traps the PBA in a liquid medium. The medium or substrate is then processed with a biochemical technique, the choice of which depends on the parameter being measured: the culturable subset of PBA is often of interest to biologists and is measured by cultivating the sample in a laboratory and counting the grown colonies. Staining and visual identification using a microscope is used to count every particle with a certain property (such as gram-negative bacteria). Optical and electron microscopy are suited to counting all PBA in a certain number of fields of view to give estimates of the airborne concentration. More recently UV flow cytometry techniques have been used to analyse prepared samples. All of these techniques have the advantage of being reliable and specifically identifying biological species but they are also time-consuming and resource intensive, reducing the practicality of sampling for long periods or with high time resolution.

\subsection{Previous global PBA budget estimates}

Owing to the lack of global PBA monitoring, global budgets have been estimated using proxy measurements such as Mannitol and organic carbon, data for which are more abundant. Penner (1995) use the difference between the estimated organic carbon emission rate and the known non-biological sources to arrive at a global PBA emission rate of $56 \mathrm{Tg} \mathrm{yr}^{-1}$ for particles larger than $1 \mu \mathrm{m}$, but state this value is subject to considerable uncertainty. Jaenicke et al. (2005) performed direct measurements of cellular material at Lake Baikal, Russia (remote continental) and Mainz, Germany (semi-rural) and, considering atmospheric residence time and other emis- sion factors, estimate a considerably larger global emission rate of $\sim 1000 \mathrm{Tg} \mathrm{yr}^{-1}$. Subsequent estimates have been closer to the former than the latter: Elbert et al. (2007) associate Mannitol with the release of fungal spores from those plants with active release mechanisms, which usually take up liquid water or water vapour until a critical point is reached, triggering the violent ejection of spores. They review worldwide Mannitol abundance in the continental boundary layer and estimate $17 \mathrm{Tg} \mathrm{yr}^{-1}$ for actively released spores. This value was scaled to include passively released spores, which require an external mechanical force for release, giving a to-

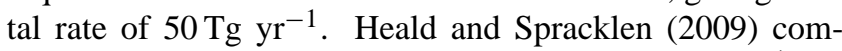
pute a global fungal spore emission rate of $28 \mathrm{Tg} \mathrm{yr}^{-1}$ using Mannitol as a tracer in their GEOS-Chem model. They found the largest mass concentration in the tropics from concentrations optimised to water vapour concentration and leaf area index (LAI) which are considered important influences. Winiwarter et al. (2009) concluded that plant debris and fungal spores dominate global PBA loadings. They used measurements of organic carbon (OC), black carbon (BC) and Levoglucosan (LG) as proxies to estimate plant debris and fungal spore emission rates from a cellulose (plant material) yield calculated when cellulose was sampled alongside OC, BC and LG. Chitin (fungal material) emission was also estimated based on the directly measured Chitin to Cellulose yield. PBA (plant debris + spores) emission factors were then calculated for each country in Europe taking land use into account. They report a European PBA emission rate of $0.233 \mathrm{Tg} \mathrm{yr}^{-1}$, suggesting a global emission rate of several $\mathrm{Tg}_{\mathrm{yr}}{ }^{-1}$.

\subsection{Environmental PBA measurements}

Absolute PBA concentrations vary widely depending on local influences. Matthias-Maser and Jaenicke (2000a) analysed airborne cellular material and found that the ratio of PBA to total aerosol number at $D_{\mathrm{P}}>0.2 \mu \mathrm{m}$ is $30 \%$ in a rural/urban influenced area and $19 \%$ in a remote continental location, corresponding to PBAP number concentrations of 1.9 and $0.22 \mathrm{~cm}^{-3}$, respectively. Measurements in Amazonia by Guyon et al. (2003) reported an average aerosol mass concentration of $3.9 \pm 1.4 \mu \mathrm{g} \mathrm{m}^{-3}$ in the coarse mode $\left(\mathrm{PM}_{10}-\mathrm{PM}_{2}\right)$. Nocturnal mass loadings were a factor of $1.9 \pm 0.4$ larger than daytime loadings. They conclude that this increase occurred because aerosol produced at the forest floor is trapped beneath a shallow nocturnal boundary layer, but do not identify the nature of the aerosol. Gilbert and Reynolds (2005) used slit impactors containing petroleum jelly-coated microscope slides to collect and count fungal spores with a light microscope. They describe diurnal fungal spore concentrations collected simultaneously in the understorey ( $1.5 \mathrm{~m}$ above the forest floor) and in the canopy (15-33 $\mathrm{m}$ above ground) of lowland tropical forest in Queensland, Australia. They observed significant spatial and temporal patterns in spore concentration, which was 
on average 52 times higher in the understorey than in the canopy, reflecting the greater proportion of fungi towards the forest floor, where the microclimate favours fungal growth (e.g. Langenberg et al., 1977). Understorey spore number rose rapidly after sunset, peaking at $1000-5000 \mathrm{~L}^{-1}$ at night and declined at daybreak, reaching $100-300 \mathrm{~L}^{-1}$ by midday. In the absence of turbulent transport supermicron particles are removed from the air within minutes through gravitational settling, leading to rapid changes in number concentration when emission ceases.

\subsection{UV-LIF detection}

In response to the threat of bio-warfare agents such as Anthrax, research over the past 15-20 years has been pursued into techniques that rapidly identify PBA in ambient aerosol using ultraviolet light induced fluorescence (UV-LIF) of particles. This fluorescence is intrinsic to certain molecules common to most biological material, specifically Tryptophan, Phenylalanine, Tyrosine, flavins, cellulose, chlorophyll (which fluoresces slightly) and the co-enzyme NADH. Tryptophan (excited near $270 \mathrm{~nm}$ and fluorescent at $300-400 \mathrm{~nm}$ ) and NADH (excited near $360 \mathrm{~nm}$ and fluorescent at 400 $600 \mathrm{~nm}$ ) dominate the fluorescence spectra from PBA in these bands because of their high fluorescence quantum yield, despite accounting for typically $1-3 \%$ of the total dry mass. They are also readily excitable at wavelengths provided by current UV lasers and lamps.

\subsection{Fluorescence from PBA and non-PBA}

Pan et al. (1999) measured the continuous fluorescence spectra from single bacterial cells and found well-defined peaks at $300-400 \mathrm{~nm}$ and a broader peak between $400-600 \mathrm{~nm}$ following a $266 \mathrm{~nm}$ excitation. In comparison, non-biological dusts such as ammonium sulphate and black carbon registered negligible fluorescence and their spectra exhibited few structural features. Particle size did not appear to influence the fluorescence spectra. The intensity of Tryptophan-like fluorescence from clusters of bacteria (Hill et al., 2001) increases in line with the cluster's absorption cross-section. One would therefore expect a UV-LIF instrument's detection efficiency to rise with the square of particle size.

Pinnick et al. (2004) measured fluorescence from ambient urban aerosol in Adelphi, USA. Fluorescence spectra from 250-700 nm were obtained from particles larger than $3 \mu \mathrm{m}$ following excitation at $266 \mathrm{~nm}$. Hierarchical cluster analysis was performed on the spectra and demonstrated that over $80 \%$ could be classified using 8 template spectra. They also conclude that fluorescence alone is not suitable for distinguishing biological from fluorescent non-biological particles following a single wavelength excitation. The same technique was used by Pan et al. (2007b) in New Haven and Las Cruces, USA; semi-urban and desert environments respectively. They detected fluorescence in $49 \%$ and $17 \%$ of all particles larger than $3 \mu \mathrm{m}$ in each location respectively. In these cases 10 template spectra could describe more than $90 \%$ of the particles sampled in both locations as well as those from Adelphi, suggesting there is comparatively little variation in the spectra of ambient fluorescent aerosol larger than $3 \mu \mathrm{m}$. Eversole et al. (2003) used an excitation wavelength of $266 \mathrm{~nm}$ to successfully detect at least $70 \%$ of test bioaerosols, and found that the majority exhibited low fluorescent intensity in the instrument's dynamic range in the wavebands $300-400 \mathrm{~nm}$ and $400-600 \mathrm{~nm}$.

Using dual-wavelength excitation (at 266 and $351 \mathrm{~nm}$ ) Hill et al. (1999) found that the fluorescence spectra of bacillus subtilis var niger (BG) vegetative cells are distinguishable from those of BG fungal spores following a $351 \mathrm{~nm}$ excitation not but following a $266 \mathrm{~nm}$ excitation. The converse was true of washed and unwashed vegetative cells. Sivaprakasam et al. (2004) sequentially excited particles at $266 \mathrm{~nm}$ and $355 \mathrm{~nm}$ and measured total fluorescent intensity in wavebands centred at 350,450 and $550 \mathrm{~nm}$. They conclude that some differentiation between different bioaerosol types (although not necessarily biological species) may be possible with multiple excitations.

\subsection{Fluorescent non-biological material}

The similar fluorescent properties of PBAP and complex mixtures of polycyclic aromatic hydrocarbons (PAHs) and other aromatics are demonstrated using cigarette smoke by Pan et al. (1999). They show that smoke's fluorescence spectrum following a $266 \mathrm{~nm}$ excitation is virtually indistinguishable from that of BG spores. The two are readily distinguishable by measuring elastic scattering patterns and overall intensity: BG spores are generally supermicron and rod-like in shape whereas smoke particles are sub-micron and multiple particles occupied the sensing volume simultaneously. This demonstrates the advantage of simultaneously measuring elastic scattering characteristics with fluorescence in reducing false positives. Decomposed plant material often contains fluorescent material such as humic acid, which can appear in soil aerosols. While biological, this is not primary biological material and is classed as an interferent likely to affect large particles.

Alongside these developments, cheaper and more portable instruments were designed that offer measurements of total fluorescence in particular wavebands that correspond to the dominant biological fluorophores. A non-exhaustive list of spectrometers is presented in Table 1, while a more complete review of current spectrometers can be found in Pan et al. (2007a). The general purpose of such instruments is to act as rapid triggers for more elaborate bioaerosol identification systems that may include biochemical techniques but that cannot be operated continuously. 


\subsection{Comparisons between conventional biosamplers and UV-LIF}

Agranovski et al. (2003) compared the TSI UVAPS (an NADH-type detector) to a liquid impinger (the AGI-30) and demonstrate that a larger number of PBAP is reported by the UVAPS than by the AGI-30. This is explained by the impinger requiring microbes to culture (reproduce) before being counted whereas the UVAPS requires viability. Culturing is more biologically demanding than viability and occurs for only a portion of the lifecycle. Agranovski and Ristovski (2005) observe that the fluorescent intensity of bacteria clusters varies depending on the stage in their lifecycle, with the most intense fluorescence associated with rapid population growth

UV-LIF instruments actually measure the fluorescent subset of PBAP, or FBAP as discussed by Huffman et al. (2010), because some PBAP fluorescence will inevitably go undetected and some PBAP may simply not fluoresce. Interference is possible from any aerosol particles with similar size, fluorescence yield, excitation and emission wavelengths to Tryptophan or NADH, as discussed earlier. These factors lead to under-estimates and over-estimates of PBAP respectively and to convey these limitations this work will use "FBAP" rather than "PBAP" to describe the observed quantities.

\subsection{The Wide Issue Bioaerosol Sensor (WIBS-3)}

In this work, measurements of fluorescence were obtained using a Wide Issue Bioaerosol Spectrometer-Model 3, or WIBS-3 (Kaye et al., 2005; Foot et al., 2008). Filtered Xenon lamps provide two sequential ultraviolet pulses centred at 280 and $370 \mathrm{~nm}$ to excite Tryptophan and NADH fluorescence in single particles. Total fluorescence is measured at 310-400 and 400-600 nm following the Tryptophan excitation and at $400-600 \mathrm{~nm}$ following the NADH excitation.

As each particle passes through a $633 \mathrm{~nm}$ diode laser beam its elastic scattering intensity is sampled in the forward direction and at a 90-degree offset. These measurements are compared with a lookup table generated by a Mie scattering model (provided by the instrument manufacturer) to estimate particle optical equivalent diameter. Forward scattering intensity is sampled at 4 angular offsets by a quadrant photomultiplier tube (PMT) allowing measurement of its distribution for each particle. The 4 values are combined, Eq. (1), to give a parameter known as the "Asymmetry Factor", AF, which describes the degree of symmetry of the intensity distribution:

$$
\mathrm{AF}=\frac{k\left(\sum_{i=1}^{n}\left(\bar{E}-E_{i}\right)^{2}\right)^{1 / 2}}{\bar{E}}
$$

where $k$ is an instrument-defined constant, $\bar{E}$ is the mean intensity measured over the entire PMT and $E_{i}$ is the inten- sity measured by the $i$ th quadrant. AF may be interpreted as a measure of the morphology of particles. Coincident or perfectly spherical single particles generate a symmetrical intensity distribution $(\mathrm{AF}=1)$ and fibres an asymmetrical one $(\mathrm{AF}=100) . \mathrm{AF}$ is also affected by whether particles that are centred in the sampling volume (aerodynamic effects) and particles that are mixtures of different refractive indices. A detailed discussion of similar measurements is provided by Kaye et al. (2007). It is difficult to attribute a specific shape to each AF but the channel allows distinction between differently-shaped aerosol subpopulations.

To characterise the performance of the WIBS-3, laboratory $\mathrm{AF}$ measurements were performed using polystyrene latex (PSL) spheres of physical diameter $1 \mu \mathrm{m}$ and $3 \mu \mathrm{m}$. Modal AF for $1 \mu \mathrm{m}$ spheres was $2-3$ units higher than for $3 \mu \mathrm{m}$, suggesting the noise in the quadrant PMT causes smaller particles to register slightly higher AF regardless of their similar shape. AF may also be interpreted as a measure of confidence in the optical sizing performance of the WIBS-3: a high $\mathrm{AF}$ represents a greater uncertainty because of the lack of particle sphericity, but by necessity optical particle sizing returns a result based on a spherical particle.

\section{Site description and instrumentation}

The WIBS-3 and associated measurements were carried out as part of the Aerosol Coupling in the Earth System (ACES) and the Oxidant, Particulate and Photochemical Processes (OP3) field campaigns in 2008 in Danum Valley, Malaysian Borneo (a project overview is available in Hewitt et al., 2010). This conservation area was established in 1981 and covers $43800 \mathrm{Ha}$, representing $4.5 \%$ of the $972804 \mathrm{Ha} \mathrm{New}$ Yayasan Sabah Concession Area (NYSCA), which is currently not logged according to Marsh and Greer (1992). The forest in Danum Valley is categorized as a tropical lowland evergreen rainforest and has an estimated average height of $35 \mathrm{~m}$ at the understorey measurement site. The area containing both measurement sites was last logged in 1988 and repopulated in the early 1990s; therefore the diversity of tree species at each site is comparable. Sunrise and sunset times were 06:00 and 18:15 LT, respectively.

The majority of the OP3 campaign measurements were based in a clearing atop a ridge at a Global Atmosphere Watch (GAW) station $\left(04^{\circ} 58^{\prime} 53^{\prime \prime} \mathrm{N}, 117^{\circ} 50^{\prime} 37^{\prime \prime} \mathrm{E}\right)$. The WIBS-3 was stationed at $7 \mathrm{~m}$ height on a tower at one end of the clearing, $5 \mathrm{~m}$ above the top of the vegetation surrounding the clearing. Other instrumentation was situated at $30 \mathrm{~m}$ height on the GAW tower at the other end of the clearing, $25 \mathrm{~m}$ above the surrounding vegetation.

The understorey site lay approximately $1 \mathrm{~km}$ to the east of the GAW site and around $200 \mathrm{~m}$ lower at the base of the ridge. The estimated canopy height was $35 \mathrm{~m}$ and dense foliage was present in the lower $5 \mathrm{~m}$. The canopy runs continuously up the side of the ridge until the edge of the GAW site. 
Table 1. omparison of some currently available UV-LIF bioaerosol spectrometers.

\begin{tabular}{|c|c|c|c|c|}
\hline Name/description & Size range & Peak excitation & $\begin{array}{l}\text { Fluorescence detection } \\
\text { band }\end{array}$ & UV light source \\
\hline UVAPS (TSI, Inc.) & $0.3 \leq D_{\mathrm{A}} \leq 20 \mu \mathrm{m}$ & $355 \mathrm{~nm}$ & $420-575 \mathrm{~nm}$ & Laser \\
\hline BAWS (Lockheed Martin) & $2-10 \mu \mathrm{m}$ & $260-280 \mathrm{~nm}$ & $\begin{array}{l}300-400 \mathrm{~nm} \\
400-600 \mathrm{~nm}\end{array}$ & Laser \\
\hline $\begin{array}{l}\text { WIBS-3 (Foot et al., 2008; } \\
\text { Kaye et al., 2005) }\end{array}$ & $0.5 \leq D_{\mathrm{P}} \leq 20 \mu \mathrm{m}$ & $280 \mathrm{~nm}$ & $\begin{array}{l}300-400 \mathrm{~nm} \\
400-600 \mathrm{~nm}\end{array}$ & $\begin{array}{l}\text { Xenon lamps w/ } \\
\text { UV filters }\end{array}$ \\
\hline & & $370 \mathrm{~nm}$ & $400-600 \mathrm{~nm}$ & \\
\hline AFS (Biral, inc) & $0.5 \leq D_{\mathrm{P}} \leq 15 \mu \mathrm{m}$ & $280 \mathrm{~nm}$ & $\begin{array}{l}330-650 \mathrm{~nm} \\
420-650 \mathrm{~nm}\end{array}$ & Laser \\
\hline SPFA (Eversole et al., 1999) & $D_{\mathrm{P}} \geq 0.5 \mu \mathrm{m}$ & $266 \mathrm{~nm}$ & $\begin{array}{l}300-400 \mathrm{~nm} \\
400-600 \mathrm{~nm}\end{array}$ & Laser \\
\hline AFSA (Hill et al., 1999) & $D_{\mathrm{P}} \geq 1 \mu \mathrm{m}$ & $266 \mathrm{~nm}$ & Continuous $200-700 \mathrm{~nm}$ & Laser \\
\hline
\end{tabular}

Solar radiation intensity recorded by net radiometers typically reached noon maxima of $1050 \mathrm{Wm}^{-2}$ and $50 \mathrm{Wm}^{-2}$ at the GAW and understorey sites, indicative of the high degree of canopy shading at the understorey site. Micrometeorological and aerosol instruments were installed at the understorey site, including a number of optical particle counters (GRIMM model 1.108 aerosol spectrometers, size range $0.3-20 \mu \mathrm{m})$. Ambient temperature $(T)$, pressure and relative humidity $(\mathrm{RH})$ were measured in the understorey using a warmed probe for improved accuracy in near condensing environments (Vaisala Model HMT 337 consisting of a PT100 RTD sensor, range -70 to $+180^{\circ} \mathrm{C}$, accuracy $\pm 0.2^{\circ} \mathrm{C}$ at $20^{\circ} \mathrm{C}$ and a HUMICAP ${ }^{\odot} 180 \mathrm{R}$ sensor, range 0 to $100 \%$ $\mathrm{RH}$, accuracy $\pm 1.0 \%$ from 0 to $90 \%$ and $\pm 1.7 \%$ from 90 to $100 \%)$. Wind speed was measured in each location by 3-D sonic anemometers $(50 \mathrm{~Hz}$ time resolution, Gill Inc. Model R3). In the understorey the WIBS-3 and a GRIMM 1.108 optical particle counter (OPC) were each connected to $1.3 \mathrm{~m}$ stainless steel tubes for which inertial particle losses are likely to dominate for $D_{\mathrm{P}}>20 \mu \mathrm{m}$. Their inlets were colocated with the micrometeorological instrumentation.

The OP3 and ACES campaigns ran in two phases: 16 April-3 May and 19 June-23 July 2008. 75 h of WIBS-3 data was obtained above the canopy from 18-23 July. In the understorey the WIBS-3 sampled for 10.5 days (19 April-3 May) and 14 days (22 June-8 July) in each campaign, respectively. Above-canopy WIBS-3 data was collected in July, after the understorey sampling, so the analysis is based on June-July data to reduce the uncertainty in comparing the two sites. The degree to which the remaining time separation affects the comparison between sites is also discussed.

\subsection{Instrument calibration and flow information}

WIBS-3 initial size calibration and verification was performed using polystyrene latex (PSL) microspheres of refractive index $n_{\mathrm{r}}=1.6$ and physical diameter 1.0, 2.1 and $3.0 \mu \mathrm{m}$ and borosilicate glass spheres $n_{\mathrm{r}}=1.56$ and physical diameter $2 \mu \mathrm{m}$. Green fluorescent PSL microspheres sized 1 and $2.1 \mu \mathrm{m}$ were used to verify the excitation and fluorescence channels were operating correctly. The WIBS-3 inlet flow rate was $2.3 \mathrm{~L} / \mathrm{min} \pm 5 \%, 90 \%$ of which was passed through HEPA filters, providing a sheath flow constraining the remaining $0.23 \mathrm{~L} / \mathrm{min}$ sample flow. The GRIMM sample flow rate was $1.2 \mathrm{~L} / \mathrm{min}$.

\subsection{WIBS-3 comparison with other instruments}

WIBS-3 data was binned to match the GRIMM OPC size channels, and both reported an understorey ambient size mode at $2-3 \mu \mathrm{m}$. The GRIMM OPC reported a large submicron number concentration with an open size distribution. The WIBS-3 (its lower size cut-off at $0.5-0.8 \mu \mathrm{m}$ ) reported a secondary mode at $1 \mu \mathrm{m}$ with number reducing at smaller sizes. The WIBS-3 total number concentration ( $N_{\text {WIBS }}$ ) best matched the GRIMM OPC number concentration $\left(N_{\text {GRIMM }}\right)$ in the GRIMM size range $0.5 \leq D_{\mathrm{P}} \leq 20 \mu \mathrm{m}$. Linear regression between the two in June-July showed that $N_{\text {WIBS }}=0.91 N_{\text {GRIMM }}\left(D_{\mathrm{P}} \geq 0.5 \mu \mathrm{m}\right)$ and their correlation coefficient $r=0.56$ was likely a result of different instrument sensitivity limits and coincidence effects at small sizes.

An Aerodynamic Particle Sizer (TSI Inc. APS, model 3321) was stationed above the canopy for the duration of the campaigns, connected to a $35 \mathrm{~m}$ high flow rate inlet stack ( $\sim 15 \mathrm{~m}$ higher than that of the WIBS-3 when it was above canopy). With both instruments on the stack the WIBS-3 reported a primary number size mode at $1-2 \mu \mathrm{m}$ and a secondary mode at $2-3 \mu \mathrm{m}$. The APS reported an open size distribution at sub-micron sizes and a secondary 
mode at $2-2.3 \mu \mathrm{m}$. The WIBS-3 was then placed at the other end of the clearing on its own $1 \mathrm{~m}$ stainless steel inlet tube, whereafter $N_{\text {WIBS }}$ best matched the APS number concentration $\left(N_{\mathrm{APS}}\right)$ at $D_{\mathrm{A}} \geq 0.96 \mu \mathrm{m}$, with $r=0.73$ and $N_{\text {WIBS }}=0.83 N_{\text {APS }}\left(D_{\mathrm{P}} \geq 0.96 \mu \mathrm{m}\right)$, significantly better than when compared with the GRIMM OPC.

\subsection{Determination of FBAP number $\left(N_{\text {FBAP }}\right)$}

Finite fluorescence intensity is always recorded by the WIBS-3 because of low-level excitation in its optical components. This baseline fluorescence is characterised by operating in "forced trigger" mode, performing measurements on an empty sensing volume. This data was collected for $24 \mathrm{~h}$ in each location and showed no underlying diurnal cycle in the fluorescent baseline. Baseline intensity in each channel is normally distributed with a standard deviation dictated by detector noise and the variability of the Xenon flash lamps, the latter monitored and found to be $\pm 3 \%$ of the mean excitation intensity. In order to distinguish between fluorescent and non-fluorescent particles in detection channel $i$, a noise threshold is defined, as in Eq. (2):

$$
E_{\mathrm{THRESHOLD}}=<E_{i}>+2.5 \sigma_{i}
$$

Any fluorescence power higher than 2.5 standard deviations $\left(2.5 \sigma_{i}\right)$ above the modal baseline $\left\langle E_{i}\right\rangle$ is classed as fluorescent. Based on a continuous normal probability distribution it is estimated that $\sim 1 \%$ of non-fluorescent particles are misclassified as fluorescent, but an unknown number of fluorescent particles inevitably go undetected through instrument sensitivity limitations. In light of this the reported fluorescent particle number is probably a lower limit of the true quantity.

The current literature concerning detailed fluorescence spectrum measurements of outdoor ambient aerosols (Pinnick et al., 2004; Pan et al., 2007b) suggests that the most likely FBAP candidates exhibit both Tryptophan-like and NADH-like fluorescence peaks. Hill et al. (1999) reported that fungal spores exhibit both types of fluorescence strongly. To try and mitigate false positives the definition of FBAP in this analysis is therefore "the number concentration of particles that exceed the noise threshold in both the Tryptophan and NADH detection channels" (i.e. at 310-400 nm following the $280 \mathrm{~nm}$ excitation and at $400-600 \mathrm{~nm}$ following the $370 \mathrm{~nm}$ excitation). This is denoted by $N_{\text {FBAP }}, N_{\text {WIBS }}$ is the total WIBS-reported number concentration and $N_{\mathrm{NON}}$ is the number of particles exhibiting no fluorescence in any channel.

It should be noted that $N_{\mathrm{NON}} \neq N_{\mathrm{WIBS}}-N_{\mathrm{FBAP}}$ because some particles exhibit Tryptophan or NADH-like fluorescence but not both. The contribution of this component at each site is discussed and treated as an uncertainty on $N_{\text {FBAP. }}$ Fluorescence measured at 400-600 nm following the $280 \mathrm{~nm}$ excitation is associated with $\mathrm{NADH}$, but is not added to the FBAP criterion as in practice it appears to artificially lower reported concentrations while being well correlated with the other channels Combining the two channels in this manner reduces the $\sim 1 \%$ thresholding uncertainty to $\sim 0.01 \%$ of $N_{\text {WIBS }}$.

The nearest large potential source of anthropogenic pollution is the town of Lahad Datu, $80 \mathrm{~km}$ away Hewitt et al., 2010) therefore it is assumed that all fluorescent coarse mode aerosol particles observed are biological in nature, since a significant number of transported coarse pollutants is unlikely. This assumption is re-evaluated throughout the manuscript using supplementary data where available to establish the reliability of the measurements.

\subsection{Data scaling and quality control}

Single-particle data were binned to 5-min time resolution and divided by the sample flow rate to find the number concentration. If two particles pass through the WIBS-3 sensing volume before the Xenon lamps have recharged (accounting for less than $10 \%$ of cases) the second particle is counted as "missed". In fewer than $0.5 \%$ of cases the Xenon lamps did not trigger, and these events are also re-designated as missed. The missed particle count (MPC) is subsequently used to scale the derived concentration and size distributions. Particles with recorded by the WIBS- 3 with $D_{\mathrm{P}} \leq 0.5 \mu \mathrm{m}$ are often caused by electrical noise and excluded from the analysis.

\section{Results and discussion}

\subsection{Meteorological conditions}

Figures 1 and 2 display the average diurnal cycles of RH and $T$ (i) in the understorey and (ii) above the canopy. The limited standard deviation (represented by boxes) of both variables in the understorey compared with above the canopy indicate the variation of $T$ and $\mathrm{RH}$ is suppressed because the canopy shields the site from incoming solar radiation and prevents efficient exchange with the air above it at night. The result is a consistent diurnal cycle of both variables and modally higher RH and $T$ at night in the understorey. Diurnally averaged wind speed for June-July is printed in Fig. 3 for (i) the top of the canopy and (ii) the WIBS-3 understorey measurement height. In both cases the maximum occurs during daylight hours, and this suggests some mixing at the top of the canopy in the early afternoon. The two cycles show similar variation but the understorey wind speed is typically less than half that at the canopy top, and is far less variable. This is consistent with the damping of air motion by the canopy.

\section{Air mass back trajectories}

To establish the likely Mesoscale influences on measured aerosol properties, backwards air mass trajectories (duration $48 \mathrm{~h}$ ) ending at the GAW site were modelled at $12-\mathrm{h}$ 


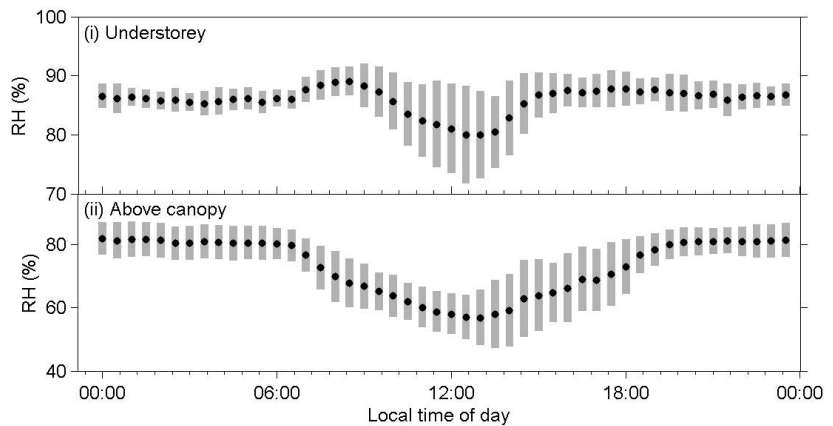

Fig. 1. Diurnal mean relative humidity (i) in the understorey and (ii) above canopy in June-July 2008. Circles represent mean RH and boxes represent \pm 1 standard deviation.

intervals for the entire campaign and hierarchically clustered by Robinson et al. (2010). Three template trajectories described the majority of modelled air mass trajectories ending at the measurement site during the June-July measurement campaign: $58 \%$ of trajectories began off the SE coast of Borneo; $18 \%$ travelled northwards over the terrain of Borneo and $14 \%$ travelled northwards along the east coast. The likely air mass influences were therefore marine, terrestrial and coastal respectively.

\subsection{Particle concentration in the forest understorey}

Figure 4 shows $N_{\text {WIBS }}, N_{\text {FBAP }}$ and $N_{\text {NON }}$ for the duration of the June-July ambient understorey measurements. A strong diurnal cycle of $N_{\text {WIBS }}$ was observed to be dominated by $N_{\text {FBAP, }}$ which peaked daily at 14:00-15:00 LT and again around midnight. A series of $N_{\text {FBAP }}$ bursts followed sunset, maintaining a concentration of $\sim 1500-2000 \mathrm{~L}^{-1}$. These bursts ceased by midnight and the concentration fell to $\sim 300 \mathrm{~L}^{-1}$ by daybreak, and to a minimum of $\sim 50 \mathrm{~L}^{-1}$ in late morning. The cycle began again at 15:00 LT and there were no systematic deviations from it, suggesting aerosol removal by rain was mitigated by interception and channelling of rainwater by the canopy. The same pattern was observed in the understorey in April-May WIBS-3 data.

$N_{\text {NON }}$ was typically $100-800 \mathrm{~L}^{-1}$ throughout the campaign and rose by $100-200 \mathrm{~L}^{-1}$ with the pronounced peaks in $N_{\mathrm{FBAP}}$, suggesting it was influenced by marginally fluorescent or non-fluorescent particles from the FBAP source. $N_{\text {NON }}$ rose independently of $N_{\text {FBAP }}$ at midday on 23, 24 and 28 June peaking at $600 \mathrm{~L}^{-1}, 1100 \mathrm{~L}^{-1}$ and $400 \mathrm{~L}^{-1}$, respectively. This behaviour was also observed on several days in the April-May measurement period. Corresponding APS number above-canopy $\left(D_{\mathrm{A}} \geq 0.96 \mu \mathrm{m}\right)$ at midday on these dates was $1000 \mathrm{~L}^{-1}, 1250 \mathrm{~L}^{-1}$ and $600 \mathrm{~L}^{-1}$, and it is plausible that the non-fluorescent material was transported from above the canopy, where the number was slightly higher during the daytime. The wind speed at the top of the canopy generally reached its maximum at this time of day and this also

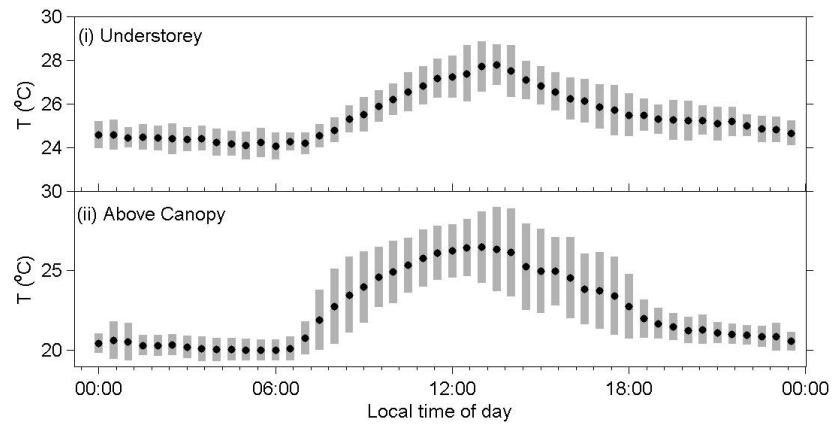

Fig. 2. Diurnal mean air temperature (i) in the understorey and (ii) above canopy in June-July 2008. Circles represent mean temperature and boxes represent \pm 1 standard deviation.

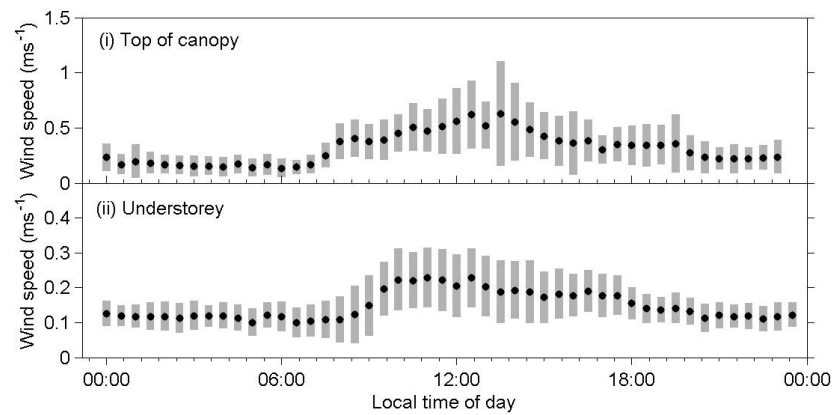

Fig. 3. Diurnal mean wind speed (i) at the top of the canopy and (ii) in the understorey, June-July 2008. Circles represent mean wind speed and boxes represent \pm 1 standard deviation.

suggests mixing at the top of the canopy may be responsible for the changes seen below, but the reason daytime $N_{\mathrm{NON}}$ enhancements were seen only on certain days is unclear.

The average diurnal cycles of (i) $N_{\text {WIBS }}$, (ii) $N_{\text {NON }}$ and (iii) $N_{\text {FBAP }}$ in the understorey are displayed in Fig. 5 . The day-to-day consistency of $N_{\mathrm{FBAP}}$ from 19:00-12:00 LT is illustrated by the small low standard deviation, and the large standard deviation between 1500-1800 demonstrates that the daily $N_{\text {FBAP }}$ spike always occurred in this time interval. The largest $N_{\mathrm{NON}}$ variations were associated with these FBAP events, outside of which $N_{\text {NON }}$ was between 200 and $400 \mathrm{~L}^{-1}$ and its standard deviation $\left(100-200 \mathrm{~L}^{-1}\right)$ throughout the rest of the day was larger than that of $N_{\mathrm{FBAP}}$. This difference in diurnal and day-to-day variability suggests the majority of $N_{\mathrm{FBAP}}$ and $N_{\mathrm{NON}}$ were from separate sources.

Mean number size distributions $\left(d N / d \log D_{\mathrm{P}}\right)$ for $N_{\mathrm{WIBS}}$, $N_{\text {NON }}$ and $N_{\text {FBAP }}$ are plotted in Fig. 6 (i), (ii) and (iii) respectively. The $N_{\text {WIBS }}$ size distribution exhibits modes at $0.8-1.6 \mu \mathrm{m}$ and $2-3 \mu \mathrm{m}$ whereas the $N_{\mathrm{FBAP}}$ distribution shows no $0.8-1.6 \mu \mathrm{m}$ mode. The size mode at 0.8 $1.6 \mu \mathrm{m}$ is dominated by $N_{\mathrm{NON}}$ and it is distinct from the $N_{\text {FBAP }}$ size mode. A minor $2-3 \mu \mathrm{m}$ enhancement appears in the $N_{\mathrm{NON}}$ size distribution, which represents $15 \%$ of 


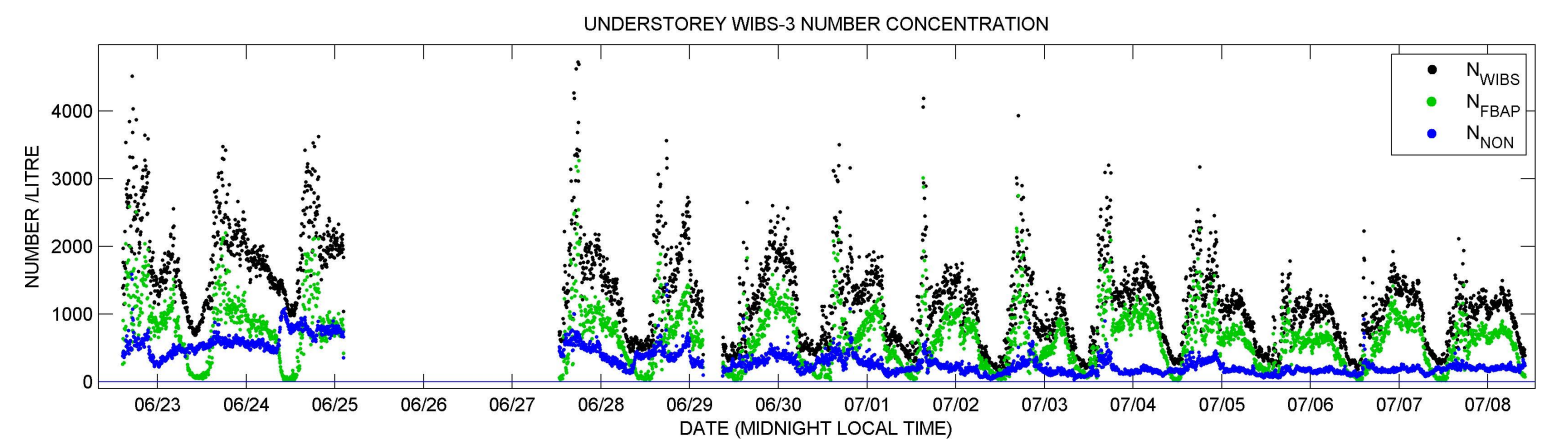

Fig. 4. Understorey time series of $N_{\text {WIBS }}, N_{\text {FBAP }}$ and $N_{\text {NON }}$, June-July 2008. The gap from 25-27 June represents instrument downtime.
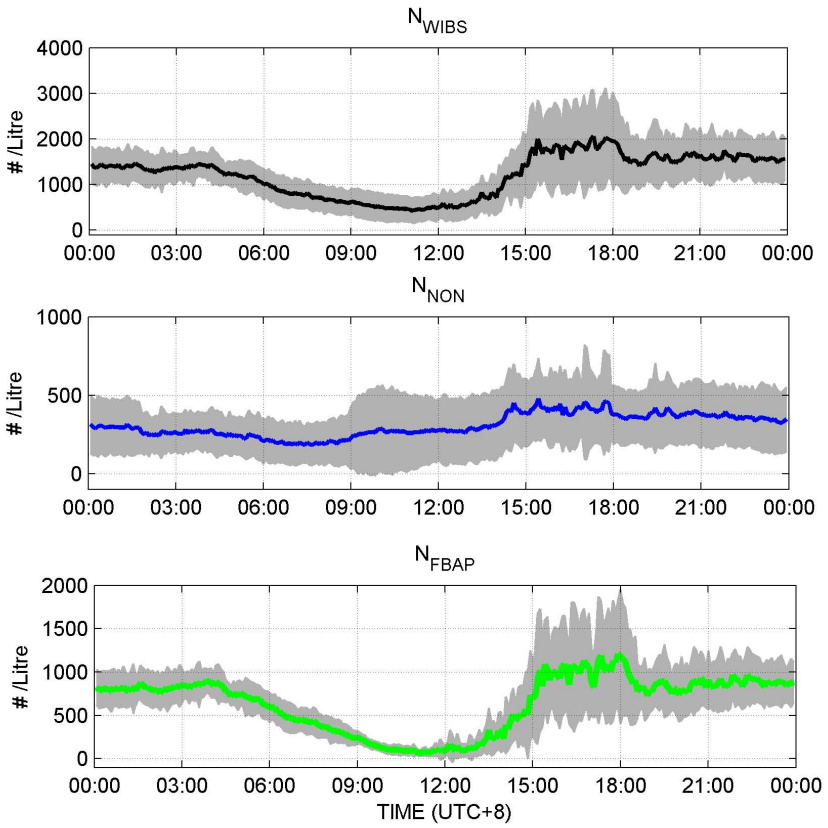

Fig. 5. Diurnal average of $N_{\mathrm{WIBS}}, N_{\mathrm{NON}}$ and $N_{\mathrm{FBAP}}$ at the understorey site. The shaded area represents \pm 1 standard deviation.

$N_{\text {FBAP }}$ at $2-3 \mu \mathrm{m}$. This feature is associated with the correlated $N_{\text {NON }}$ and $N_{\text {FBAP }}$ in mid-afternoon. Timeresolved plots of these distributions are printed in Supplementary Fig. S3 (see http://www.atmos-chem-phys.net/10/ 4453/2010/acp-10-4453-2010-supplement.pdf).

Like $N_{\mathrm{FBAP}}$, diurnally averaged $\mathrm{RH}$ in the understorey (Fig. 1i) also reaches a peak (albeit the second peak of the day) at 14:00-17:00 LT, suggesting the two may be related. The nature of such a relationship would likely be active fungal spore release triggered by $\mathrm{RH}$ reaching $80 \%$. If this is the case, the spore supply would be exhausted on a timescale of $1 \mathrm{~h}$ and replenished during the daytime. A measured diameter of several microns is also consistent with fungal spores. The plot in Fig. 7 shows that peak $N_{\text {FBAP }}$ typically coincides with RH levels between $80-90 \%$ and $N_{\text {FBAP }}$ reduces out-
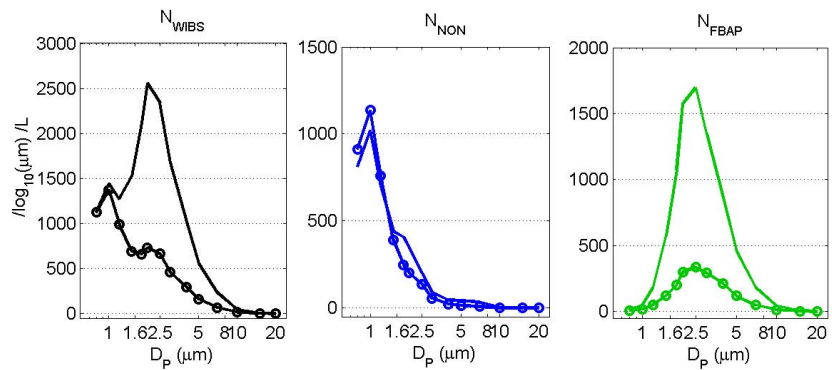

Fig. 6. Number size distributions in the understorey and above canopy for (i) $N_{\text {WIBS }}$, (ii) $N_{\text {NON }}$ and (iii) $N_{\text {FBAP }}$. Circular points denote above-canopy measurements.

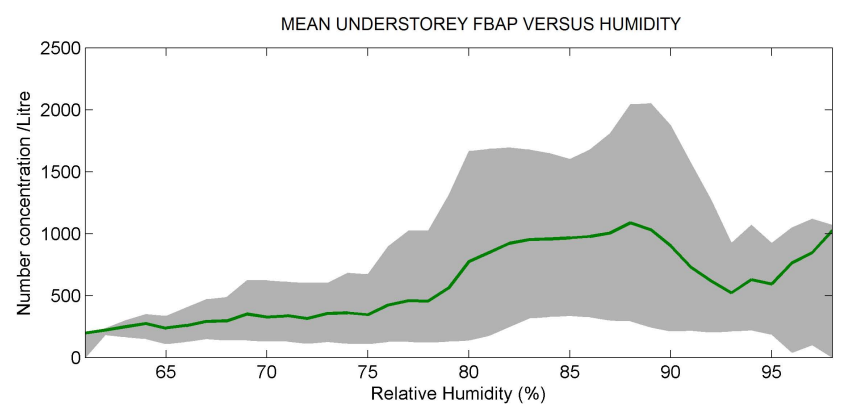

Fig. 7. Understorey $N_{\text {FBAP }}$ as a function of ambient RH. Line depicts the mean $N_{\text {FBAP }}$ and the shaded region the interval between the 10th and 90th percentiles.

side of this range. The link between RH (and temperature) and spore release is well documented (e.g. Meredith, 1963; Grinn-Gofroñ and Mika, 2008) with the exact conditions for spore release governed by the plant species.

\section{Understorey particle concentration after WIBS-3 departs}

The understorey time series of $N_{\text {WIBS }}$ and $N_{\text {GRIMM }}\left(D_{\mathrm{P}} \geq 0.5 \mu \mathrm{m}\right)$ both report a gradual decline in the maximum number concentration at the peak of the diurnal cycle. Figure 8 depicts understorey $N_{\text {GRIMM }}\left(D_{\mathrm{P}} \geq 0.5 \mu \mathrm{m}\right)$ 

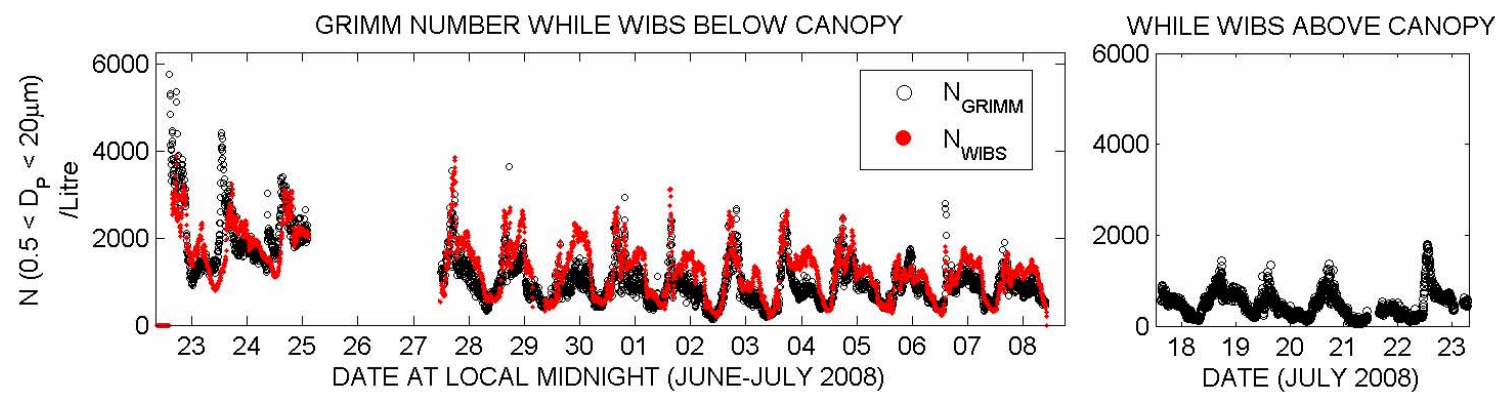

Fig. 8. Time series of understorey $N_{\text {GRIMM }}\left(0.5 \leq D_{\mathrm{P}} \leq 20 \mu \mathrm{m}\right)$ throughout the WIBS-3 measurement campaigns and understorey $N_{\mathrm{WIBS}}$. Instrument downtime occurred from 25-27 June.

while the WIBS-3 was at each location, as well as $N_{\text {WIBS }}$ while the two were co-located. The daily peak in $N_{\text {GRIMM }}$ began to decline after 27 June, falling from $4000 \mathrm{~L}^{-1}$ to $1000 \mathrm{~L}^{-1}$ by 8 July. The mean nocturnal $N_{\text {GRIMM }}$ in the final week fell to 0.35 its previous value, but that around noon does not change significantly. It is therefore plausible (but unconfirmed) that the decline results from a reduction in the FBAP emission rate.

The cluster analysis of air mass backward trajectories in Robinson et al. (2010) shows that the three air mass influences dominated for several days apiece, yet the WIBS-3 data in the understorey shows no corresponding multi-day changes in $N_{\text {FBAP. }}$. Robinson et al. (2010) also note that the mass spectra from an Aerodyne HR-ToF-AMS above the canopy do not contain evidence of fresh (i.e. local) biomass burning aerosols in the submicron size range. It is therefore probable that the majority of the understorey FBAP are (i) not transported a significant distance and (ii) not false positives from complex hydrocarbon interferents related to biomass burning.

\subsection{Particle concentration above canopy}

Figure 9 depicts the above-canopy time series of $N_{\text {WIBS }}$, $N_{\text {NON }}$ and $N_{\text {FBAP. }} N_{\text {WIBS }}$ is quite variable day-to-day, ranging from $300 \mathrm{~L}^{-1}$ to $1000 \mathrm{~L}^{-1}$. This variability is partly because the above-canopy environment is exposed to frequent heavy rain showers, particularly after the 20 July. $N_{\text {NON }}$ ranged from $300-800 \mathrm{~L}^{-1}$, dominating $N_{\text {WIBS }}$ and driving its variation until 21 July, with instances of larger $N_{\text {FBAP }}$ lasting several hours thereafter. $N_{\text {FBAP }}$ was highest at night and varied from $50-300 \mathrm{~L}^{-1}$, with $800 \mathrm{~L}^{-1}$ observed on 23 July. During the latter period $N_{\mathrm{FBAP}}$ recovered more rapidly (by 1-2 h) than $N_{\text {NON }}$ following rain, suggesting much of $N_{\text {NON }}$ was transported from a distant source.

Figure 10 contains the diurnally averaged above-canopy (i) $N_{\text {WIBS }}$, (ii) $N_{\text {NON }}$ and (iii) $N_{\text {FBAP. }} N_{\text {WIBS }}$ was consistently $500-700 \mathrm{~L}^{-1}$ and was dominated by $N_{\mathrm{NON}}$, which exhibits little diurnal variation but both are variable day-to-day, as illustrated by their large standard deviations compared with that of $N_{\text {FBAP. }} N_{\text {FBAP }}$ was more variable over the ave- rage day and consistent day-to-day, reducing from $200 \mathrm{~L}^{-1}$ at night to $50 \mathrm{~L}^{-1}$ at noon. Diurnal $N_{\mathrm{FBAP}}$ enhancements occurred at 15:00 LT and 21:00 LT (the latter produced by a single event in the original time series). The $N_{\text {FBAP }}$ diurnal pattern therefore resembles that found in the understorey insofar as both have a mid-afternoon enhancement and rise at night.

\subsubsection{Above-canopy number size distributions}

The plots in Fig. 6 marked by circles show are mean above-canopy $d N / d \log D_{\mathrm{P}}$ for (i) $N_{\mathrm{WIBS}}$, (ii) $N_{\text {NON }}$ and (iii) $N_{\text {FBAP. }}$ As in the understorey $N_{\text {WIBS }}$ exhibits two modes: at $0.8-1.6 \mu \mathrm{m}$ and at $2-3 \mu \mathrm{m}$. Again these are dominated by $N_{\mathrm{NON}}$ and $N_{\mathrm{FBAP}}$, respectively. The $N_{\mathrm{FBAP}}$ peak falls from 1600 to $300 L^{-1} \log (\mu \mathrm{m})^{-1}$ from the understorey to the GAW site, whereas the $N_{\text {NON }}$ peak at 0.8 $1 \mu \mathrm{m}$ rises slightly, from 1000 to $1100 L^{-1} \log (\mu \mathrm{m})^{-1}$. Timeresolved size distributions are plotted in the Supplementary Fig. S4 (see http://www.atmos-chem-phys.net/10/4453/ 2010/acp-10-4453-2010-supplement.pdf).

Given the much weaker diurnal variation compared to that in the understorey it is more difficult to attribute the abovecanopy $N_{\text {FBAP }}$ to biological material, but the faster recovery of $N_{\mathrm{FBAP}}$ following rain suggests its source is local. Its size distribution is also similar to that below the canopy. Abovecanopy measurements of the sub-micron aerosol chemical composition using an Aerodyne Aerosol Mass Spectrometer at this site are discussed elsewhere in the current special issue, and these were found to be mainly sulphate and oxidised organic particles.

\subsubsection{Before WIBS-3 was present above-canopy}

A TSI Aerodynamic Particle Sizer (Model 3320, TSI Inc.) was used to measure the number concentration of particles in the aerodynamic size interval $0.5 \leq D_{\mathrm{A}} \leq 20 \mu \mathrm{m}$. Its size measurement technique is different to that of the WIBS3 (time-of-flight versus elastic scattering intensity respectively). Both instruments identified a secondary size mode: the WIBS-3 at $2-3 \mu \mathrm{m}$ and the APS at $2-2.3 \mu \mathrm{m}$, indicating 


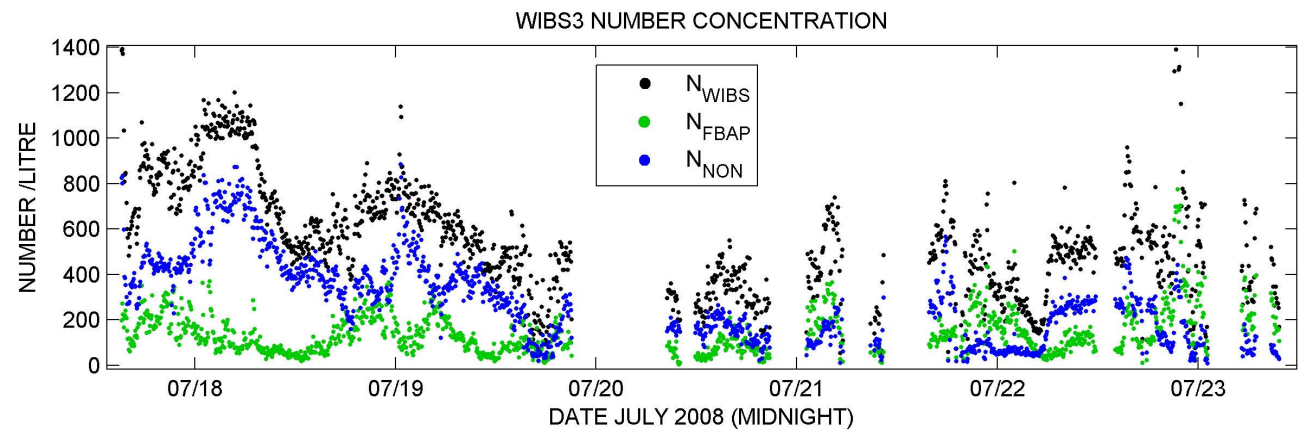

Fig. 9. Above-canopy time series of $N_{\mathrm{WIBS}}, N_{\mathrm{FBAP}}$ and $N_{\mathrm{NON}}$ in July 2008. Gaps represent instrument downtime.
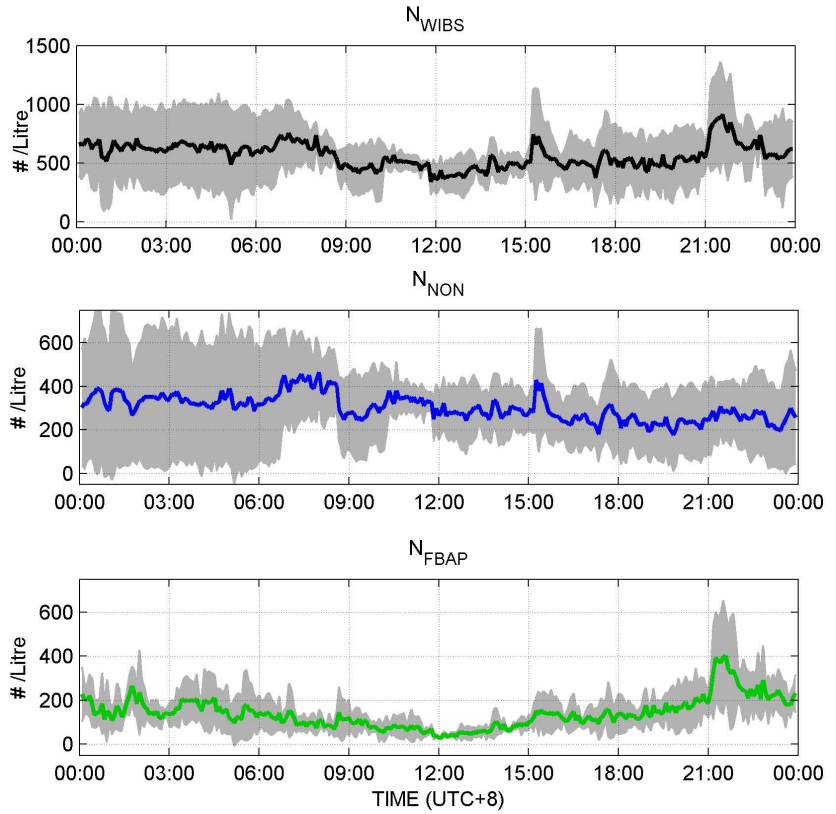

Fig. 10. Diurnal average of $N_{\text {WIBS }}, N_{\text {NON }}$ and $N_{\text {FBAP }}$ at the abovecanopy site. The shaded area represents \pm 1 standard deviation.

the two size measurements are approximately comparable here. $N_{\text {WIBS }}$ was best matched by the APS total number at $D_{\mathrm{A}} \geq 0.96 \mu \mathrm{m}$ and it is plotted in Fig. 11 with APS measurements from the entire June-July campaign for comparison. The systematic difference between the instruments from 13 to 16 July was caused by a WIBS-3 pump issue, subsequently corrected, and this data is not included in the analysis. $N_{\text {APS }}\left(D_{\mathrm{A}} \geq 0.96 \mu \mathrm{m}\right)$ reached $1600 \mathrm{~L}^{-1}$ on 25 June and shows the wide range of values obtained by the WIBS-3 is generally representative of June and July.

\subsection{Differences between understorey and above-canopy aerosol}

\subsubsection{FBAP concentration}

$N_{\text {FBAP }}$ above the canopy was typically $200 \mathrm{~L}^{-1}$ whereas below it frequently exceeded $1500 \mathrm{~L}^{-1}$. Although this difference may be partially attributed to the decline in understorey number concentration, $N_{\mathrm{APS}}\left(D_{\mathrm{A}} \geq 0.96 \mu \mathrm{m}\right)$ did not reach number concentrations in excess of $1000 \mathrm{~L}^{-1}$ after 29 July whereas data from the WIBS-3 and GRIMM OPC show this occurred regularly in the understorey, reducing the likelihood that the understorey FBAP was transported from the air above-canopy. The extra particles therefore likely originated at some point(s) between the forest floor and the top of the canopy, and were emitted with high diurnal regularity. Wind speed alone, which can mechanically suspend soil dust containing fluorescent humic substances (from decomposed biomass) and liberate some types of spores, bacteria and detritus from plant surfaces, cannot account for the variation observed since it was slightly anti-correlated $(r=-0.17)$ with fluorescent particle number in the understorey. The observed rainfall pattern was also not so regular as to explain the understorey number variation.

\subsubsection{AF distributions in each location}

AF data were split into several arbitrary size bands for understorey and above-canopy data and their frequency distributions, each normalised to its own maximum, are plotted respectively in Fig. $12 \mathrm{i}$ and ii. Both sites indicate a modal AF of 5 for particles smaller than 2-3 $\mathrm{m}$, which systematically shifts to 20 for larger particles. This type of result has been reported before, by Pan et al. (1999) who show the elastic scattering pattern from cigarette smoke is homogeneous because of particle coincidence effects and low scattering intensity whereas single BG spores create heterogeneous, intense patterns, which would lead to a higher AF here. 


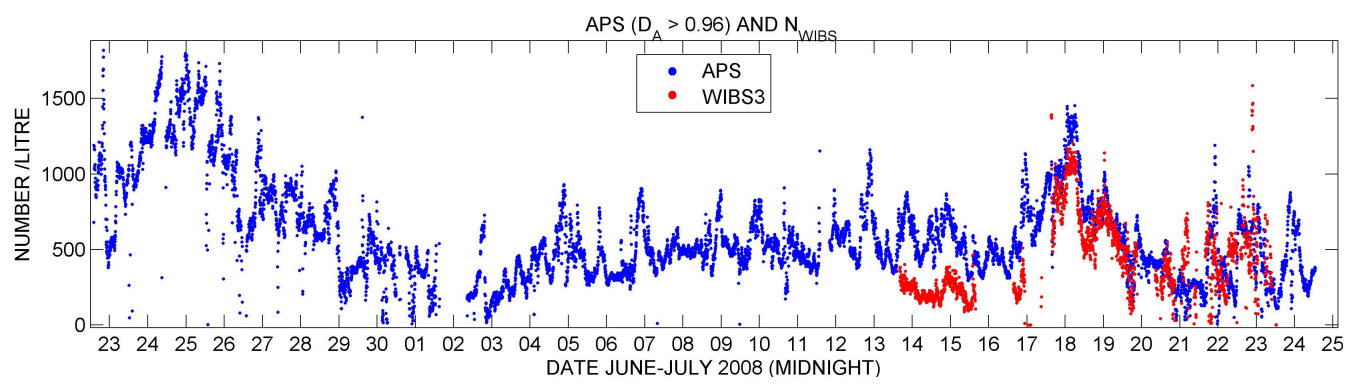

Fig. 11. Above-canopy number concentration time series from the APS and WIBS-3 in their common size range.

Above the canopy the transition to the high-AF regime is not complete until the 4-6 $\mu \mathrm{m}$ size interval is reached, because neither $N_{\mathrm{FBAP}}$ nor $N_{\mathrm{NON}}$ dominates at 2-3 $\mu \mathrm{m}$. The detected aerosol at each measurement location therefore appears to be morphologically similar based on AF. FBAP has significantly different AF properties to non-FBAP and the largest FBAP is the least uniformly spherical, as evidenced by slight increases with size in the high-AF regime. That the smaller particles have lower AF rather than higher gives confidence that the observed distributions are not merely a sizerelated artefact as was the case with the PSL microsphere experiment discussed earlier.

\subsection{Comparison of FBAP and non-FBAP at the two sites}

The ratio $N_{\mathrm{ABOVE}} / N_{\mathrm{UNDERSTOREY}}$ of the mean size distribution at each site is plotted for $N_{\mathrm{WIBS}}, N_{\mathrm{NON}}$ and $N_{\mathrm{FBAP}}$ respectively in Fig. 13. To estimate the uncertainty in these relative size distributions the fractional standard deviation at each point in each size distribution was propagated in quadrature. The time separation of the two measurements means the derived ratios cannot be considered a direct comparison but they are helpful in comparing the typical features of the aerosol sampled at each location.

In each case a steep fall in ratio occurs from $0.8-1.6 \mu \mathrm{m}$, coinciding with the transition from the smaller size mode to the larger at each site. At larger sizes the standard deviation of $N_{\mathrm{FBAP}}$ reduces and the ratio begins to rise gradually with particle size, from 0.25 at $1.6 \mu \mathrm{m}$ to 0.4 at $15 \mu \mathrm{m}$, albeit with increasing standard deviation as $N_{\text {WIBS }}$ reduces significantly at the largest sizes. $N_{\text {NON }}$ initially follows the same pattern as $N_{\text {FBAP }}$ but also exhibits an enhancement at 2-5 $\mu \mathrm{m}$ that may be linked to the reduction in Tryptophan-type fluorescence above the canopy. Another enhancement occurs at $10 \mu \mathrm{m}$ but uncertainty dominates here. The excess of $N_{\mathrm{NON}}$ above the canopy suggests it is entrained into the understorey environment rather than originating there.

\subsection{Uncertainty in FBAP classification}

The number of fluorescent particles that do not meet the FBAP criterion offers an insight into the potential under-estimate of FBAP number. A linear regression
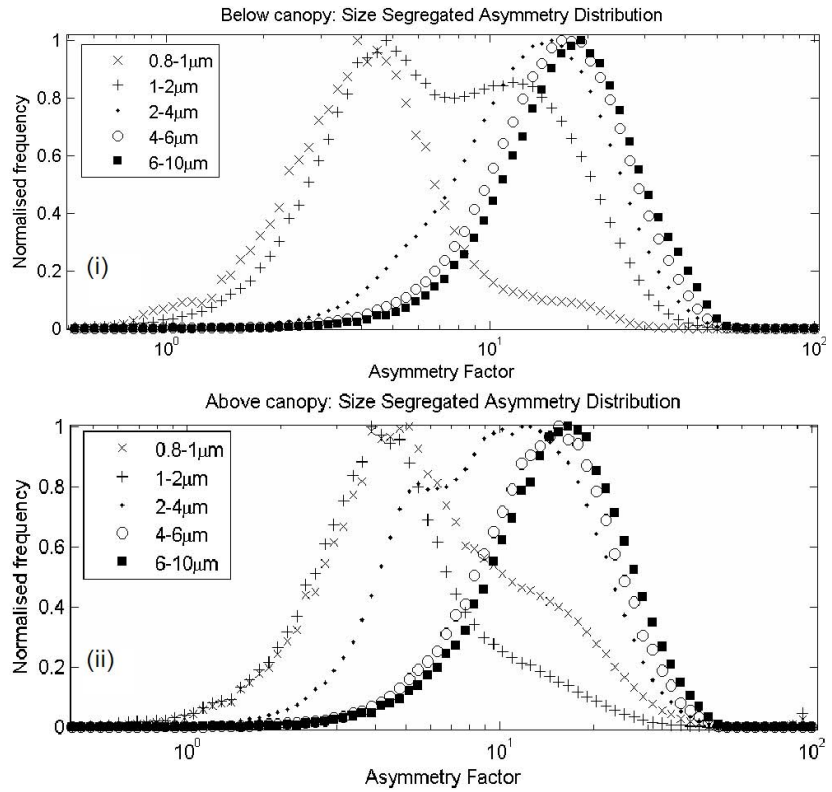

Fig. 12. Normalised Asymmetry Factor distributions (i) in the understorey and (ii) above the canopy, segregated by particle size.

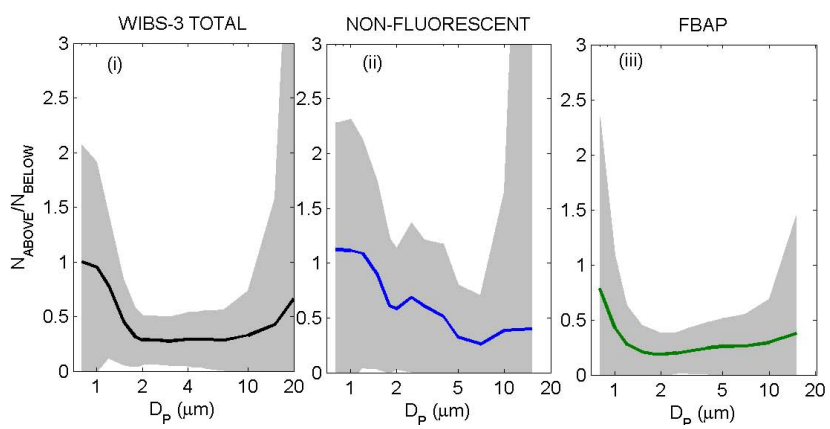

Fig. 13. Above canopy:understorey number concentration ratio as a function of particle size for (i) $N_{\mathrm{WIBS}}$, (ii) $N_{\mathrm{NON}}$ and (iii) $N_{\mathrm{FBAP}}$, with \pm 1 standard deviation highlighted in grey.

between $N_{\mathrm{NADH}}$ and $N_{\mathrm{TRYPTOPHAN}}$ shows that mean $N_{\mathrm{NADH}}=0.97 N_{\mathrm{TRYP}}$ in the understorey, with $r=0.98$. Above the canopy $N_{\mathrm{NADH}}$ dominates, with $N_{\mathrm{TRYP}}=0.66 N_{\mathrm{NADH}}$ 
with $r=0.90$, suggesting the presence of a different fluorescent aerosol component or a consequence of the understorey FBAP being exposed to the strong solar UV radiation above the canopy. This type of uncertainty is therefore small in the understorey but represents almost a third of $N_{\text {FBAP }}$ above the canopy. Time series of $N_{\mathrm{NADH}}$ and $N_{\text {TRYP }}$ are printed for the understorey and above-canopy sites (Figs. S1 and S2, see http://www.atmos-chem-phys.net/10/ 4453/2010/acp-10-4453-2010-supplement.pdf) to illustrate the systematic difference between the two components above the canopy and their similarity in the understorey.

\section{Comparison with other studies}

Based on the similarity in aerosol properties but significant difference in $N_{\text {FBAP }}$ at the two sites it appears there is little sustained or prolonged FBAP transport between them. This is reflected in a more complete analysis of aerosol fluxes between the sites by Whitehead et al. (2010). Based on simultaneous measurements at each site they conclude that only submicron-sized particles bear the hallmarks of transport between the sites and this transport is limited to periods in late morning. They also measure vertical profiles of supermicron aerosol number using a series of optical particle counters between the forest floor (where the WIBS-3 was stationed) and canopy top. Mid-afternoon number spikes were observed matching the $N_{\text {FBAP }}$ spikes measured by the WIBS-3 but these were confined to the lower half of the understorey, suggesting a lack of vertical transport.

Gilbert and Reynolds (2005) counted spores in the understorey of a tropical forest in Queensland, Australia, and found a strong diurnal cycle with concentrations ranging from $\sim 10^{2} \mathrm{~L}^{-1}$ in daylight to $\sim 10^{3} \mathrm{~L}^{-1}$ at night, comparing favourably with the values obtained in our study. They found the mean understorey spore concentration is 52 times higher than within the canopy, a significantly stronger gradient than in this study, which shows mean above canopy $N_{\text {FBAP }}$ is a factor of 2.5 smaller than in the understorey. The major uncertainty from non-simultaneous WIBS-3 measurements is capable only of reducing this derived value, since the understorey FBAP diurnal cycle appears to diminish later in the campaign. Based on our measurements the majority of understorey FBAP emanates from below the canopy but it is unclear exactly what height contributes the most. Windliberated material from the top of the canopy does not appear to affect understorey $N_{\text {FBAP }}$ but may affect that found above canopy, possibly explaining the larger discrepancy between $N_{\text {NADH }}$ and $N_{\text {TRYP }}$ found there. Above-canopy $N_{\text {FBAP }}$ (on average $\sim 150 \mathrm{~L}^{-1}$ ) compares favourably with MatthiasMaser and Jaenicke (2000b) who report remote continental PBAP concentration of $220 \mathrm{~L}^{-1}$ at $D_{\mathrm{P}}>0.2 \mu \mathrm{m}$, although material smaller than the WIBS-3 can detect may contribute to their results.
Guyon et al. (2003) observed a 1.9 \pm 0.4 -fold increase in total coarse $\left(\mathrm{PM}_{10}-\mathrm{PM}_{2}\right)$ mass at night in Amazonia, but do not distinguish between PBAP and other coarse aerosol particles. Our study finds the coarse aerosol to be dominated by FBAP, with mean night-time $N_{\text {FBAP }} 1.8$ times higher than daytime in both the understorey and above canopy, albeit with standard deviations of 1.8 and 1.6, respectively, because of intense understorey $N_{\text {FBAP }}$ fluctuations in mid-afternoon and small $N_{\text {FBAP }}$ above canopy. Gilbert and Reynolds (2005) found mean nocturnal spore concentration was 5.7 times the daytime value in the understorey, and canopy-level concentrations increased by a factor of 35 at night. These understorey values are of similar magnitude to those obtained with the WIBS-3 in the understorey, but the longer term decline in diurnal cycle strength observed illustrates how the cycle intensity is subject to change, although its qualitative behaviour is maintained throughout. The vertical gradient results may differ significantly because Gilbert and Reynolds' upper measurement site was within the canopy rather than high above it as in this study. A different vertical arrangement of FBAP sources through the canopy at each forest would also explain the difference.

\section{Summary and conclusions}

Single-particle ultraviolet light-induced fluorescence was used to identify the fluorescent subset of the primary biological aerosol in the size range $0.8-20 \mu \mathrm{m}$ above and below the canopy of a tropical rainforest. The size, morphology and number concentration of the fluorescent and non-fluorescent components at each site was compared.

The understorey $N_{\text {WIBS }}$ is dominated by $N_{\text {FBAP }}$ but this is not the case above the canopy, where $N_{\text {FBAP }}$ is an order of magnitude smaller although $N_{\text {NON }}$ is comparable at both sites. The understorey $N_{\text {FBAP }}$ diurnal cycle is remarkably consistent and exhibits strong enhancements in midafternoon and early evening as well as elevated number at night. Mean nocturnal $N_{\text {FBAP }}$ enhancement is similar at both sites but the strong transient features observed in the understorey are not observed above the canopy. The gentler variation of the above-canopy $N_{\text {FBAP }}$ cycle qualitatively suggests only a weak coupling of FBAP between the sites. In the understorey it appears that a number of non-FBAP particles are contributed by the FBAP emission mechanism. The aerosol turbulent transport below and above canopy is discussed in further detail in the associated paper by Whitehead et al. (2010) in this special issue

Based on observed recovery times of above-canopy $N_{\mathrm{NON}}$ and $N_{\text {FBAP }}$ following rain showers, and the measured dayto-day variability of $N_{\mathrm{NON}}$ compared to that of $N_{\mathrm{FBAP}}$, the two do not appear to share the same source, with the FBAP source lying closer to the measurement sites. This conclusion is reinforced by the comparable $N_{\mathrm{NON}}$ but consistently larger $N_{\text {FBAP }}$ in the understorey. The apparent independence of the 
understorey $N_{\text {FBAP }}$ diurnal cycle from wind speed, abovecanopy coarse mode number concentration and calculated air mass origin suggest that it is produced within or below the canopy. The largest $N_{\text {FBAP }}$ values were measured when understorey RH was greater than $80 \%$, suggesting a potential link. Such behaviour is consistent with actively released fungal spores, the supply of which may be exhausted through the evening and replenished throughout the daytime. The $N_{\text {FBAP }}$ size mode at $3 \mu \mathrm{m}$ and presence of fluorescence in multiple wavelength bands is also consistent with small fungal spores.

The common size and Asymmetry factor (AF) modes obtained at both sites indicate that the same sources of FBAP and non-FBAP contribute significantly to each site. The forest is concluded to be the source of most FBAP observed in each location, but it is unclear whether the top of the canopy acts as a more significant source of FBAP at the abovecanopy site than in the understorey. This may account for the larger difference between $N_{\mathrm{NADH}}$ and $N_{\mathrm{TRYP}}$ above canopy.

A gradual day-to-day decline in the intensity of the understorey $N_{\text {FBAP }}$ diurnal cycle was observed later in the WIBS3 dataset and continued after the WIBS-3 was moved to the above-canopy site. Coarse mode aerosol number concentration measured using a TSI APS stationed above the canopy for the entire campaign did not reflect the strength of the diurnal cycle observed below. This indicates FBAP are significantly attenuated by the canopy and/or are only weakly transported between the sites by the intermediate atmosphere. Since the source is thought to lie outside the canopy, this difference in abundance compared with FBAP may arise because of the direction of travel through the canopy: FBAP are larger and must be propagated upwards against a strong sedimentation flux gradient by intermittent large scale turbulence events (see Whitehead et al., 2010) whereas the nonfluorescent particles are smaller and appear to be entrained into the understorey.

Acknowledgements. This is paper number 502 of the Royal Society's South East Asian Rainforest Research Programme. This work was funded by the Natural Environment Research Council (award NE/F00866X/1). The OP3 project was funded by the UK Natural Environment Research Council (NE/D002117/1). Measurements made in the understorey were performed as part of the ACES (Aerosol Coupling in the Earth System) project of the NERC APPRAISE programme (Aerosol Properties, PRocesses And Influences on the Earth's Climate). We thank the Malaysian and Sabah Governments for their permission to conduct research in Malaysia; the Malaysian Meteorological Department (MMD) for access to the Bukit Atur Global Atmosphere Watch station; W. Sinun of Yayasan Sabah and his staff and G. Reynolds of the Royal Society's South East Asian Rain Forest Research Programme and his staff for logistical support at the Danum Valley Field Centre.

Edited by: A. B. Guenther

\section{References}

Agranovski, V., Ristovski, Z., Hargreaves, M., Blackall, P. J., and Morawska, L.: Real-time measurement of bacterial aerosols with the UVAPS: Performance evaluation, J. Aerosol Sci., 34, 301317, 2003.

Agranovski, V. and Ristovski, Z. D.: Real-time monitoring of viable bioaerosols: capability of the UVAPS to predict the amount of individual microorganisms in aerosol particles, J. Aerosol Sci., 36, 665-676, 2005.

Deihl, K., Quick, C., Matthias-Maser, S., Mitra, S. K., and jaenicke, R.: The ice nucleating ability of pollen Part I: Laboratory studies in deposition and condensation freezing modes, J. Atmos. Res., 75-87, 2001.

Deihl, K., Quick, C., Matthias-Maser, S., Mitra, S. K., and jaenicke, R.: The ice nucleating ability of pollen Part II: Laboratory studies in immersion and contact freezing modes, J. Atmos. Res., 75-87, 2002.

Elbert, W., Taylor, P. E., Andreae, M. O., and Pöschl, U.: Contribution of fungi to primary biogenic aerosols in the atmosphere: wet and dry discharged spores, carbohydrates, and inorganic ions, Atmos. Chem. Phys., 7, 4569-4588, 2007,

http://www.atmos-chem-phys.net/7/4569/2007/.

Eversole, J. D., Hardgrove, J. J., Cary Jr, W. K., Choulas, D. P., and Seaver, M.: Continuous, rapid biological aerosol detection with the use of UV fluorescence: Outdoor test results, Field Anal. Chem. Tech., 3, 249-259, 1999.

Eversole, J. D., Scotto, C. S., Spence, M., and Campillo, A. J.: Continuous bioaerosol monitoring using UV excitation fluorescence, 19th Congress of the International Commission for Optics: Optics for the Quality of Life, 532-533, 2003.

Foot, V. E., Kaye, P. H., Stanley, W. R., Barrington, S. J., Gallagher, M., and Gabey, A.: Low-cost real-time multiparameter bio-aerosol sensors, Optically Based Biological and Chemical Detection for Defence IV, Cardiff, Wales, UK, 71160I-71112, 2008.

Gilbert, G. S. and Reynolds, D. R.: Nocturnal Fungi: Airborne Spores in the Canopy and Understory of a Tropical Rain Forest, Biotropica, 37, 462-464, 2005.

Grinn-Gofroñ, A. and Mika, A.: Selected airborne allergenic fungal spores and meteorological factors in Szczecin, Poland, 20042006, Aerobiologia, 24, 89-97, 2008.

Guyon, P., Graham, B., Roberts, G. C., Mayol-Bracero, O. L., Maenhaut, W., Artaxo, P., and Andreae, M. O.: In-canopy gradients, composition, sources, and optical properties of aerosol over the Amazon forest, J. Geophys. Res., 108(D18), 4591, doi:10.1029/2003JD003465, 2003.

Heald, C. L. and Spracklen, D. V.: Atmospheric budget of primary biological aerosol particles from fungal spores, Geophys. Res. Lett., 36, L09806, doi:10.1029/2009GL037493, 2009.

Hewitt, C. N., Lee, J. D., MacKenzie, A. R., Barkley, M. P., Carslaw, N., Carver, G. D., Chappell, N. A., Coe, H., Collier, C., Commane, R., Davies, F., Davison, B., DiCarlo, P., Di Marco, C. F., Dorsey, J. R., Edwards, P. M., Evans, M. J., Fowler, D., Furneaux, K. L., Gallagher, M., Guenther, A., Heard, D. E., Helfter, C., Hopkins, J., Ingham, T., Irwin, M., Jones, C., Karunaharan, A., Langford, B., Lewis, A. C., Lim, S. F., MacDonald, S. M., Mahajan, A. S., Malpass, S., McFiggans, G., Mills, G., Misztal, P., Moller, S., Monks, P. S., Nemitz, E., Nicolas-Perea, V., Oetjen, H., Oram, D. E., Palmer, P. I., 
Phillips, G. J., Pike, R., Plane, J. M. C., Pugh, T., Pyle, J. A., Reeves, C. E., Robinson, N. H., Stewart, D., Stone, D., Whalley, L. K., and Yin, X.: Overview: oxidant and particle photochemical processes above a south-east Asian tropical rainforest (the OP3 project): introduction, rationale, location characteristics and tools, Atmos. Chem. Phys., 10, 169-199, doi:10.5194/acp-10169-2010, 2010.

Hill, S. C., Pinnick, R. G., Niles, S., Pan, Y.-L., Holler, S., Chang, R. K., Bottiger, J., Chen, B. T., Orr, C.-S., and Feather, G.: Realtime measurement of fluorescence spectra from single airborne biological particles, Field Anal. Chem. Technol., 3, 221-239, 1999.

Hill, S. C., Pinnick, R. G., Niles, S., Fell, N. F., Pan, Y.-L., Bottiger, J., Bronk, B. V., Holler, S., and Chang, R. K.: Fluorescence from Airborne Microparticles: Dependence on Size, Concentration of Fluorophores, and Illumination Intensity, Appl. Optics, 40, 3005-3013, 2001.

Huffman, J. A., Treutlein, B., and Pöschl, U.: Fluorescent biological aerosol particle concentrations and size distributions measured with an Ultraviolet Aerodynamic Particle Sizer (UV-APS) in Central Europe, Atmos. Chem. Phys., 10, 3215-3233, 2010, http://www.atmos-chem-phys.net/10/3215/2010/.

Jaenicke, R. and Matthias-Maser, S.: The direct contribution of the biosphere to the atmospheric aerosol, Aerosol Sci., 24, 537-538, 1993.

Kaye, P. H., Stanley, W. R., and Hirst, E.: Single particle multichannel bio-aerosol fluorescence sensor, Opt. Express, 13, 35833593, 2005.

Kaye, P. H., Aptowicz, K., Chang, R. K., Foot, V., and Videen, G.: Angularly Resolved Elastic Scattering from Airborne Particles, Opt. Biol. Part., 31-61, 2007.

Marsh, C. W. and Greer, A. G.: Forest Land-Use in Sabah, Malaysia - an Introduction to Danum Valley, Philos. T. Roy. Soc. B., 335, 331-339, 1992.

Matthias-Maser, S. and Jaenicke, R.: The size distribution of primary biological aerosol particles in the multiphase atmosphere, Aerobiologia, 16, 207-210, 2000.

Matthias-Maser, S., Obolkin, V., Khodzer, T., and Jaenicke, R.: Seasonal variation of primary biological aerosol particles in the remote continental region of Lake Baikal/Siberia, Atmos. Environ., 34, 3805-3811, 2000.

Meredith, D. S.: Violent Spore Release in Some Fungi Imperfecti, Ann Bot., 27, 39-47, 1963.

Möhler, O., DeMott, P. J., Vali, G., and Levin, Z.: Microbiology and atmospheric processes: the role of biological particles in cloud physics, Biogeosciences, 4, 1059-1071, doi:10.5194/bg-4-10592007, 2007.
Pan, Y.-L., Eversole, J. D., Kaye, P. H., Foot, V., Pinnick, R. G., Hill, S. C., Mayo, M. W., Bottiger, J. R., Huston, A., Sivaprakasam, V., and Chang, R. K.: Bio-aerosol Fluorescence, Opt. Biol. Part., 63-164, 2007a.

Pan, Y.-L., Pinnick, R. G., Hill, S. C., Rosen, J. M., and Chang, R. K.: Single-particle laser-induced-fluorescence spectra of biological and other organic-carbon aerosols in the atmosphere: Measurements at New Haven, Connecticut, and Las Cruces, New Mexico, J. Geophys. Res., 112, D24S19, doi:10.1029/2007JD008741, 2007.

Pan, Y., Holler, S., Chang, R. K., Hill, S. C., Pinnick, R. G., Niles, S., Bottiger, J. R., and Bronk, B. V.: Real-time detection and characterization of individual flowing airborne biological particles: fluorescence spectra and elastic scattering measurements, Air Monitoring and Detection of Chemical and Biological Agents II, Boston, MA, USA, 117-125, 1999.

Penner, J. E.: Carbonaceous aerosols influencing atmospheric radiation: Black and organic carbon in: Climate Change 2001: The Scientific Basis. Contribution of Working Group I to the Third Assessment Report of the Intergovernmental Panel on Climate Change, edited by: Houghton, J. T., Ding, Y., Griggs, D. J., Noguer, M., Linden, P. J. v. d., Dai, X., Maskell, K., and Johnson, C. A., Cambridge University Press, Cambridge, 289-348, 1995.

Pinnick, R. G., Hill, S. C., Pan, Y.-L., and Chang, R. K.: Fluorescence spectra of atmospheric aerosol at Adelphi, Maryland, USA: measurement and classification of single particles containing organic carbon, Atmos. Environ., 38, 1657-1672, 2004.

Prospero, J. M., Blades, E., Mathison, G., and Naidu, R.: Interhemispheric transport of viable fungi and bacteria from Africa to the Caribbean with soil dust, Aerobiologia, 21, 1-19, 2005.

Robinson, N. H., Newton, H., Allan, J. D., Irwin, M., Lee, J., Chen, Q., Martin, S. T., McFiggans, G., and Coe, H.: Source attribution during the OP3 project using backwards air mass trajectories, Atmos. Chem. Phys. Discuss., in preparation, 2010.

Sivaprakasam, V., Huston, A., Scotto, C., and Eversole, J.: Multiple UV wavelength excitation and fluorescence of bioaerosols, Opt. Express, 12, 4457-4466, 2004.

Whitehead, J. D., Gallagher, M. W., Dorsey, J. R., Robinson, N., Gabey, A. M., Coe, H., McFiggans, G., Flynn, M. J., Ryder, J., Nemitz, E., and Davies, F.: Aerosol fluxes and dynamics within and above a tropical rainforest in South-East Asia, Atmos. Chem. Phys. Discuss., 10, 12023-12061, doi:10.5194/acpd-10-120232010, 2010.

Winiwarter, W., Bauer, H., Caseiro, A., and Puxbaum, H.: Quantifying emissions of primary biological aerosol particle mass in Europe, Atmos. Environ., 43, 1403-1409, 2009. 